\title{
DESENVOLVIMENTO DE UM SISTEMA PRODUTO-SERVIÇO EM UMA FABRICANTE DE PRÉ-MOLDADOS DE CONCRETO
}

Antonio Erlindo Braga Junior (erlindo@uepa.br) - Universidade do Estado do Pará (UEPA)

José Carlos de Toledo (toledo@dep.ufscar.br) - Universidade Federal de São Carlos (UFSCar)

\section{RESUMO}

O trabalho apresenta um caso prático de desenvolvimento e implantação de um Sistema Produto-Serviço (SPS) em uma empresa fabricante de pré-moldados de concreto. O Sistema foi desenvolvido usando o método da pesquisa-ação, conduzida pelo pesquisador e por um grupo de profissionais da empresa. Adotou-se o modelo de Vezzoli, Kohtala e Srinivasan (2014) como o método para desenvolvimento do SPS. O produto fornecido é de propriedade do cliente e o sistema incluiu diversos serviços associados ao produto, como meio de aproveitar as competências da empresa, aumentar seu faturamento e melhorar a satisfação e custos dos clientes. Tanto o método da pesquisa-ação quanto o método adotado para desenvolvimento do SPS se mostraram adequados para atingimento dos objetivos pretendidos. A contribuição deste trabalho está na apresentação do detalhamento de um caso prático de implantação de um SPS que agrega serviços a um produto fornecido e de propriedade do cliente. Também mostra um caso sobre o potencial de implantação de SPS, e de obtenção de resultados positivos, em um setor tradicional da economia, como é caso do setor de construção civil.

Palavras chave: Sistema Produto-Serviço; Pesquisa-Ação; Desenvolvimento. 


\section{INTRODUÇÃ̃}

Este trabalho relata a implantação de um Sistema Produto-Serviço (SPS) em uma empresa fabricante de pré-fabricados em concreto e que opera no modelo engineer to order. Atende predominantemente outras empresas, caracterizando uma atuação business-to-business (B2B) fornecendo produtos como: lajes, blocos, meio fio, pisos, blocos de piso e painéis, mas também oferece produtos customizados como: vigas, pilares, blocos de fundação, dentre outros. Os produtos são manufaturados por encomenda, e a empresa mantém o nível do estoque de insumos baixo e o layout produtivo é flexível. Foi fundada em 1997 e é considerada de médio porte. No mercado em que atua os produtos possuem baixa diferenciação e a competição é definida pelo preço e com baixa oferta de soluções de serviços para o consumidor final.

O SPS foi desenvolvido e implantado seguindo o método da pesquisa-ação, conforme o modelo de Coughlan e Coghlan (2002). Cada ciclo da pesquisa ação foi definido como a realização de uma fase do método de desenvolvimento de Sistemas Produto-Serviço proposto por Vezzoli, Kohtala e Srinivasan (2014). Este método é caracterizado por uma estrutura modular e flexível, podendo ser adaptado às necessidades específicas das empresas e foi considerado mais adequado a este caso. A estrutura básica desse método de desenvolvimento de SPS consiste em quatro fases:

a) Análise estratégica - Recolher e processar informações para a geração de um conjunto de ideias com potencial para serem exploradas. É compreendida a situação da empresa, o contexto socioeconômico e as dinâmicas que a influenciam.

b) Levantamento de oportunidades - Identificar orientações para o desenvolvimento do SPS. Ocorre por meio de um processo participativo através do qual diversos atores geram ideias. O objetivo é usar as informações coletadas na fase anterior e delinear uma possibilidade estratégica.

c) Projeto de conceitos do sistema - Desenvolver as ideias mais promissoras definindo o conjunto de produtos e serviços que compõem a nova oferta.

d) Detalhamento do sistema - São especificados os recursos do sistema desenvolvido, a partir do conceito gerado na etapa anterior, para implantação.

\section{MÉTODO DE PESQUISA}


O SPS foi desenvolvido seguindo a estrutura de uma pesquisa-ação composta pelas etapas preparatória, principais e de monitoramento, conforme Coughlan e Coghlan (2002). Na etapa preparatória a atividade exploratória objetivou o melhor entendimento do negócio da empresa e de sua cultura de trabalho. Para o comprometimento dos participantes, na pesquisa-ação, procurou-se sensibilizar para a importância da participação nas discussões e execução das tarefas e cuidar dos fatores motivadores para a implantação do SPS.

Após a etapa preparatória foram iniciados os ciclos que executaram as etapas principais e a de monitoramento.

Para a adequação da pesquisa-ação com as fases do método de desenvolvimento do SPS, de Vezzoli, Kohtala e Srinivasan (2014), estabeleceu-se como objetivo de cada ciclo atingir o objetivo das fases de desenvolvimento. Para cada fase foi cumprido um ciclo da pesquisa-ação realizando-se as etapas de coleta de dados, feedback, análise dos dados, planejamento da ação, implantação e avaliação. A figura 1 apresenta a execução da Pesquisa-Ação e o método de desenvolvimento do PSS.

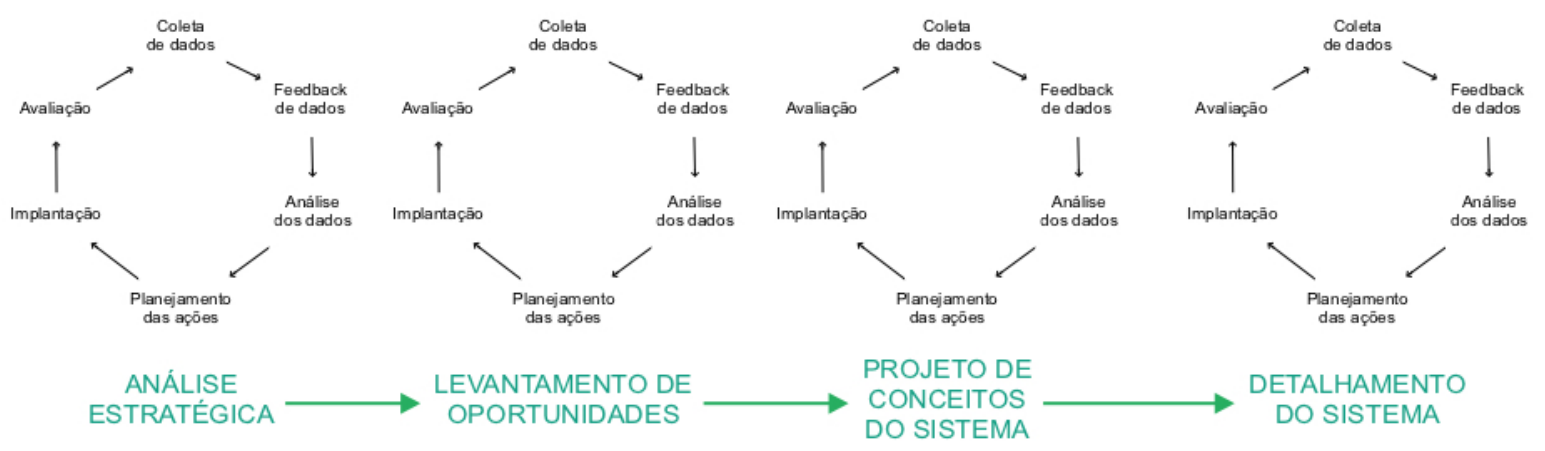

FIGURA 1 - Execução dos ciclos da Pesquisa-Ação e das fases do método de desenvolvimento de PSS

\section{A PESQUISA AÇÃO}

\subsection{Etapa Preparatória}

\subsubsection{Pesquisa exploratória}

Foram feitas visitas à linha de produção, ao escritório, a clientes onde se acompanhou operações como: projeto dos produtos, montagem de fôrmas, preparação e montagem de ferragens, gestão de operações, preparação de concreto, desforma, içamento e montagem de peças pré-fabricadas, 
orientação técnica para a consolidação de estruturas, ajustes de projeto, ajustes de montagem, dentre outros. Nesta atividade observou-se os diferenciais da empresa, características do mercado e informações a respeito da tecnologia de pré-moldados como: restrições técnicas, comparação de custos com outras modalidades construtivas e benefícios gerados.

\subsubsection{Comprometimento dos participantes}

Esta etapa foi realizada com a participação de pessoal dos níveis de gerência e de supervisão dos setores de projeto, orçamento, produção e assistência ao cliente onde houve o levantamento de suas expectativas sobre o SPS, repasse de informações técnicas a respeito do conceito de SPS, suas responsabilidades no desenvolvimento do sistema e esclarecimentos sobre o método de pesquisa-ação.

Cada grupo de profissionais da empresa necessitava de conhecimentos distintos para cumprir o seu papel na implantação do SPS. Estes conteúdos de capacitação foram definidos a partir do proposto por Nguyen, Schnürmacher e Stark (2014). Os gestores devem estar familiarizados com a teoria do SPS e o seu desenvolvimento na empresa. Os supervisores por serem responsáveis pela implantação do SPS e controlar o curso do projeto têm necessidade de conhecimento sobre a teoria, o método de desenvolvimento, a lista de requisitos e a abordagem para a introdução do SPS na empresa. Os funcionários de nível operacional receberam conceitos básicos do SPS e os benefícios para a empresa.

\subsection{Ciclo de Análise Estratégica}

Os objetivos deste ciclo foram:

a) Compreender a situação existente e saber mais sobre a empresa, contexto socioeconômico em que opera e as dinâmicas que influenciam nesse contexto;

b) Processar informações, através das quais será orientado o processo de concepção para a geração de soluções.

A partir destas diretrizes buscou-se definir o escopo do SPS para a geração de um conjunto de ideias com potencial de exploração e determinar o novo posicionamento do negócio. Esta etapa foi realizada analisando-se a empresa (seus objetivos, áreas de expertise, suas forças e fraquezas, o valor entregue) e o contexto. Foi elaborado um questionário para a realização de uma pesquisa semiestruturada com o intuito de se levantar estas informações, seguindo o clássico modelo de análise de competitividade. 
Os dados foram apresentados ao grupo para a verificação do seu correto entendimento assim como de sua validação, chegando-se às seguintes informações:

a) À época da análise a empresa enfrentava problemas financeiros, com dívidas acumuladas em função de decisões que não alcançaram o resultado esperado, possuía baixo faturamento, variedade grande no porte de clientes, ineficiência no departamento comercial da empresa;

b) O setor de produção possuía problemas de eficiência e custo fixo alto em virtude de capacidade ociosa elevada e baixa produtividade;

c) A equipe estava sem ânimo, apesar de sua competência técnica;

d) O proprietário da empresa possuía reconhecimento no mercado de cálculo estrutural da região, sendo responsável por um número significativo de projetos de prédios, pontes e outros empreendimentos;

e) O mercado local possuía características peculiares relacionadas a produtos com baixo valor agregado e um leque de opções significativamente estreito;

f) O mercado local de pré-fabricados em concreto ajustou-se a competir pelo preço;

g) A empresa tinha em seus procedimentos, e enraizada em sua cultura, a busca da diferenciação pela qualidade. Entretanto, esta estratégia era ineficaz frente à concorrência por preços;

h) A reconhecida competência técnica da equipe e a qualidade de seus produtos geravam um bom relacionamento entre a empresa e seus clientes;

i) Havia potencial demanda por produtos e serviços relacionados ao mercado de pré-fabricados em concreto com melhores resultados em custo, lead time e layout na obra.

A partir destas informações o grupo elaborou uma matriz SWOT com o objetivo de compreensão do posicionamento da oferta atual e identificação dos pontos fortes e fracos do modelo de negócios.

\section{FORCAS (Strengths)}

- O mercado reconhece a competência técnica da empresa;

- Equipe tecnicamente competente;

- Principal gestor é bem visto no mercado;

- Boa qualidade do produto em termos construtivos;

- Bom relacionamento com clientes. 


\section{FRAQUEZAS (Weakness)}

- A gestão de vendas da empresa é mal executada;

- Variedade grande no perfil dos clientes exigindo muitos tipos de abordagem e sobrecarga do setor comercial da empresa;

- Setor de produção ineficiente;

- Equipe desmotivada;

- Sem margens para competir por preços;

- Produtos sem diferenciação.

\section{OPORTUNIDADES (Opportunities)}

- O mercado apresenta produtos "commoditizados";

- Alto potencial de crescimento do mercado de peças mais complexas;

- Demanda pela oferta de serviços diferenciados.

\section{AMEACAS (Threats)}

- O mercado absorve somente produtos com baixo valor agregado;

- O mercado desconhece as possibilidades de uso de peças pré-fabricadas com maior complexidade (pouco uso em estruturas);

- O mercado está acostumado a definir a competição unicamente pelo menor preço.

A ameaça que trata do desconhecimento por parte do mercado sobre "as possibilidades de uso de peças pré-fabricadas com maior complexidade" pode ser considerada uma oportunidade a ser explorada por vislumbrar a inexistência de empresas atuando neste segmento do mercado.

\subsection{Ciclo de Levantamento de Oportunidades}

Este ciclo objetivou estabelecer um novo posicionamento para a empresa a partir das informações anteriores. Avaliando-se o cenário levantado na Análise Estratégica foi verificada a necessidade de reposicionar a empresa no mercado buscando mostrar seus diferenciais em relação aos concorrentes.

Os produtos da empresa são considerados maduros no mercado e, por este motivo, a incorporação de serviços à oferta de valor teria potencial para novos negócios. O faturamento da empresa apresenta temporadas de alta e baixa. Em períodos de muita chuva a atividade na Construção Civil diminui. Por outro lado, a empresa precisa remunerar a força de trabalho ao 
longo do ano. Esta é uma razão para que procure receitas fora de época adicionando elementos de serviços.

A opção pela oferta de serviços ganhou relevância a partir da identificação de um dos pontos fortes da empresa que é o know how em cálculo estrutural e a inexistência de empresas do setor que integram produtos e serviços. Esta alternativa foi considerada interessante por não demandar mudança significativa na cultura da empresa, porém apresentava a dificuldade de desenvolver uma estratégia de comunicar isto ao mercado e identificar quais alternativas deveriam ser seguidas para que houvesse percepção de valor no novo posicionamento da empresa.

Como primeiro passo para a definição do novo posicionamento da empresa deliberou-se pela escolha do tipo de SPS que seria adotado. Considerando a classificação de Clayton, Backhouse e Dani (2012), que ampliaram a realizada por Tukker (2004), descartou-se as classificações em que a propriedade do produto é da empresa. Não há como reutilizar uma peça estrutural de préfabricado em concreto em uma edificação distinta da sua concepção original. Para os préfabricados em concreto não existe possibilidade de compartilhamento de produtos.

O tipo "orientado ao produto" era mais apropriada ao novo posicionamento da empresa, já que estabelece que serviços de valor agregado adicionais sejam oferecidos como parte integrante da oferta. Outros benefícios para este tipo de SPS são barreiras menores de aceitação por parte dos clientes e a maior fidelização do cliente.

O grupo da pesquisa-ação definiu quais serviços seriam incluídos no portfólio. Foi concebida uma listagem de serviços a partir da modalidade de trabalho conhecida no mercado como turnkey, onde uma única empresa cuida de todos os elementos da obra, do projeto ao acabamento. Esta modalidade tem a vantagem de concentrar em um só fornecedor a responsabilidade por todas essas etapas, além de maior redução do custo.

Foram listados os potenciais serviços a serem oferecidos e a equipe fez uma adaptação da listagem levantada para o contexto do negócio e definiu os serviços que passaria a ofertar e estão organizadas no quadro 1.

QUADRO 1- Listagem de serviços sugeridos pela equipe

\begin{tabular}{|l|}
\hline Serviços pré-produção: \\
\hline Orientação técnica \\
\hline Orientações para recebimento de pré-fabricados \\
\hline Projeto (estrutural, complementar e/ou arquitetônico) \\
\hline Desenvolvimento de produtos (soluções especiais para demandas específicas) \\
\hline
\end{tabular}




\begin{tabular}{|l|}
\hline Orçamento e planejamento \\
\hline Serviços pós-produção: \\
\hline Demolição \\
\hline Canteiro remoto \\
\hline Execução de estruturas "in loco" \\
\hline Montagem e consolidação \\
\hline Acompanhamento na montagem (nivelamento, aprumo, alinhamento) \\
\hline Assistência Técnica \\
\hline
\end{tabular}

A orientação técnica vem a ser a realização de diagnósticos e avaliações com o intuito de indicar a viabilidade ou não do uso de pré-fabricados em concreto. Além de orientar o cliente na escolha da alternativa mais interessante também apresenta ao cliente que a empresa pode viabilizar uma solução completa para sua demanda. As orientações para recebimento de pré-fabricados são recomendações da empresa para clientes em situações em que é necessária uma infraestrutura de recebimento das peças no local da obra. Está relacionado a ajustes na obra, espaço disponível para içamento das peças, entre outros. O projeto é a concepção de soluções estruturais, arquitetônicas e complementares (elétrica, hidráulica ou sanitária) que a empresa oferece com um diferencial de potencializar os pontos positivos das estruturas pré-fabricadas.

No desenvolvimento de produtos são criadas soluções para demandas específicas. Nestes casos são realizados projetos, construção de fôrmas, especificação de materiais e testes para peças fora do padrão. Busca-se criar soluções para as questões observadas nas etapas de construção, transporte, armazenamento, instalação e uso. Buscou-se o aumento da participação de produtos customizados no faturamento da empresa, com maior demanda por serviços.

$\mathrm{O}$ orçamento e o planejamento são complementares ao projeto e não são ofertados conjuntamente para atender aos casos em que o cliente já possua um projeto pronto e demanda somente a sua execução. A demolição libera elementos construtivos para a execução do novo projeto e para o recebimento das peças produzidas. O canteiro remoto vem a ser a execução de elementos construtivos na obra do cliente, nos casos em que é necessária uma preparação para o recebimento das peças.

A execução de estruturas in loco será oferecida para os casos em que o projeto determina que sejam erguidas estruturas moldadas no local. A montagem e consolidação indicarão os procedimentos necessários para a junção das partes para que estrutura fique estável e consolidada. O acompanhamento na montagem é a orientação para o nivelamento, aprumo e alinhamento das peças, serviço complementar à montagem e consolidação. A assistência 
técnica é um serviço de diagnóstico e execução de soluções para problemas causados pela empresa por seus produtos e serviços, ou com origens distintas a esta.

\subsection{Ciclo de Projeto de Conceitos do Sistema}

Este ciclo teve como objetivo detalhar a oportunidade identificada na etapa anterior. Com a definição da classe do SPS a ser implantado e a listagem dos serviços oferecidos, o grupo deliberou que seria pertinente o desenvolvimento de um novo modelo de negócios. O método escolhido foi o proposto por Osterwalder e Pigneur (2010) conhecido como Business Model Canvas em virtude de sua facilidade de desenvolvimento e de posterior disseminação na empresa. Foram apresentados os nove elementos que constituem o Canvas: proposta de valor, segmentos de clientes, canais de distribuição, relacionamento com clientes, fontes de receita, recursos-chave, atividades-chave, parceiros-chave e estrutura de custos. O grupo definiu cada um destes elementos e a relação entre si, gerando o Quadro 2.

QUADRO 2 - Business Model Canvas gerado para a empresa

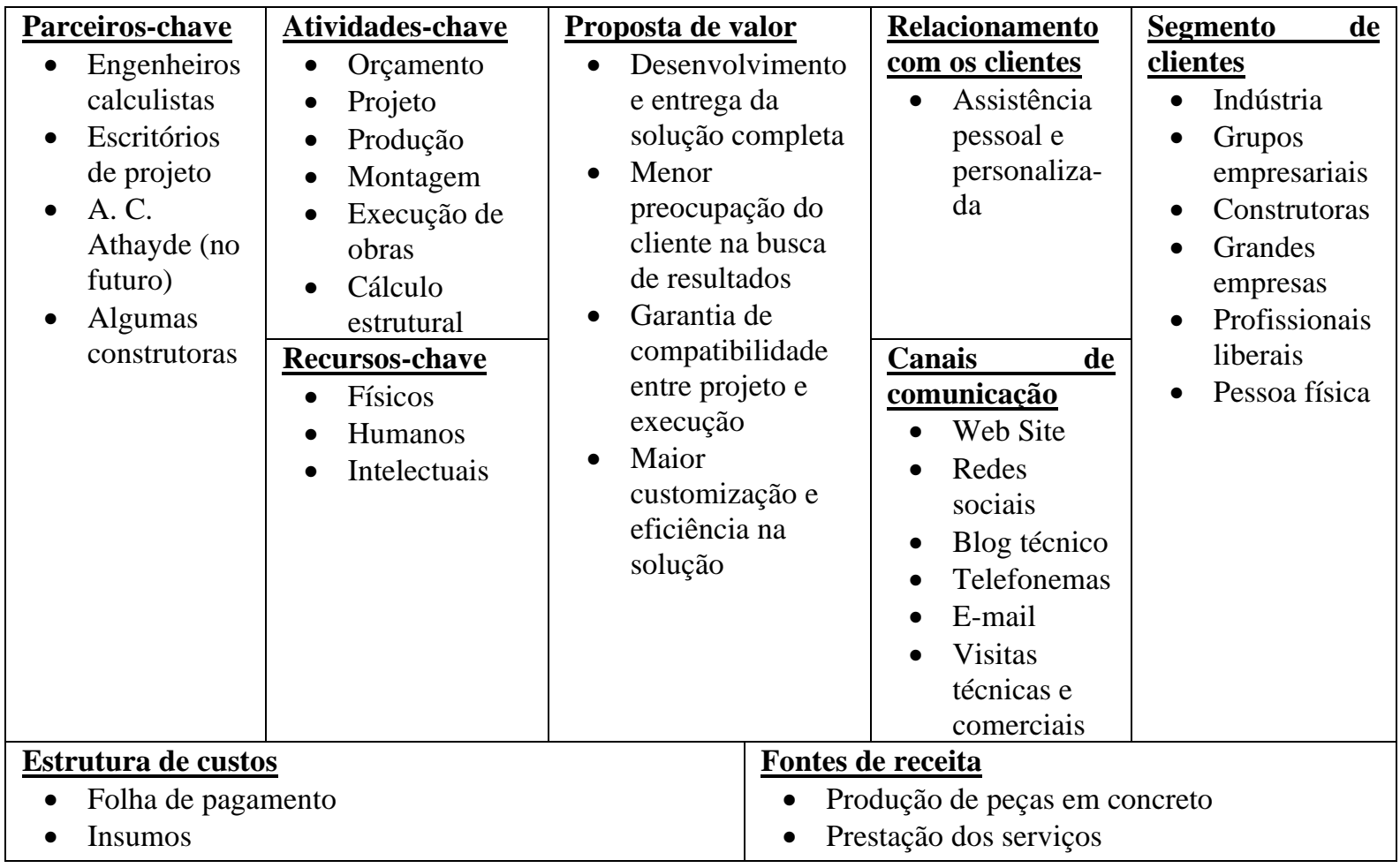


Para a conclusão desta etapa foi desenvolvido o mapa do sistema SPS com objetivo apoiar a concepção e visualização da estrutura do modelo, indicando os atores envolvidos e interações. O grupo estabeleceu as seguintes etapas do processo:

a) O processo é iniciado por um dos potenciais clientes da empresa por meio de solicitação ou ainda por um dos parceiros-chave (engenheiros calculistas, escritórios de projeto e construtoras) que pode desenvolver o projeto ou fazer a indicação da empresa para o cliente final;

b) A empresa faz o orçamento e planejamento para a execução dos produtos e serviços desejados pelo cliente;

c) A empresa aciona seus fornecedores de insumos para que possa efetuar a produção das peças e aciona seus funcionários para a prestação dos serviços, ou faz uma contratação temporária;

d) Os produtos são entregues e os serviços são realizados obedecendo a ordem estabelecida no planejamento.

No mapa do sistema (Figura 2) as linhas pontilhadas indicam fluxo de informação, as linhas espessas indicam fluxo de material e as linhas finas indicam o fluxo de serviço.

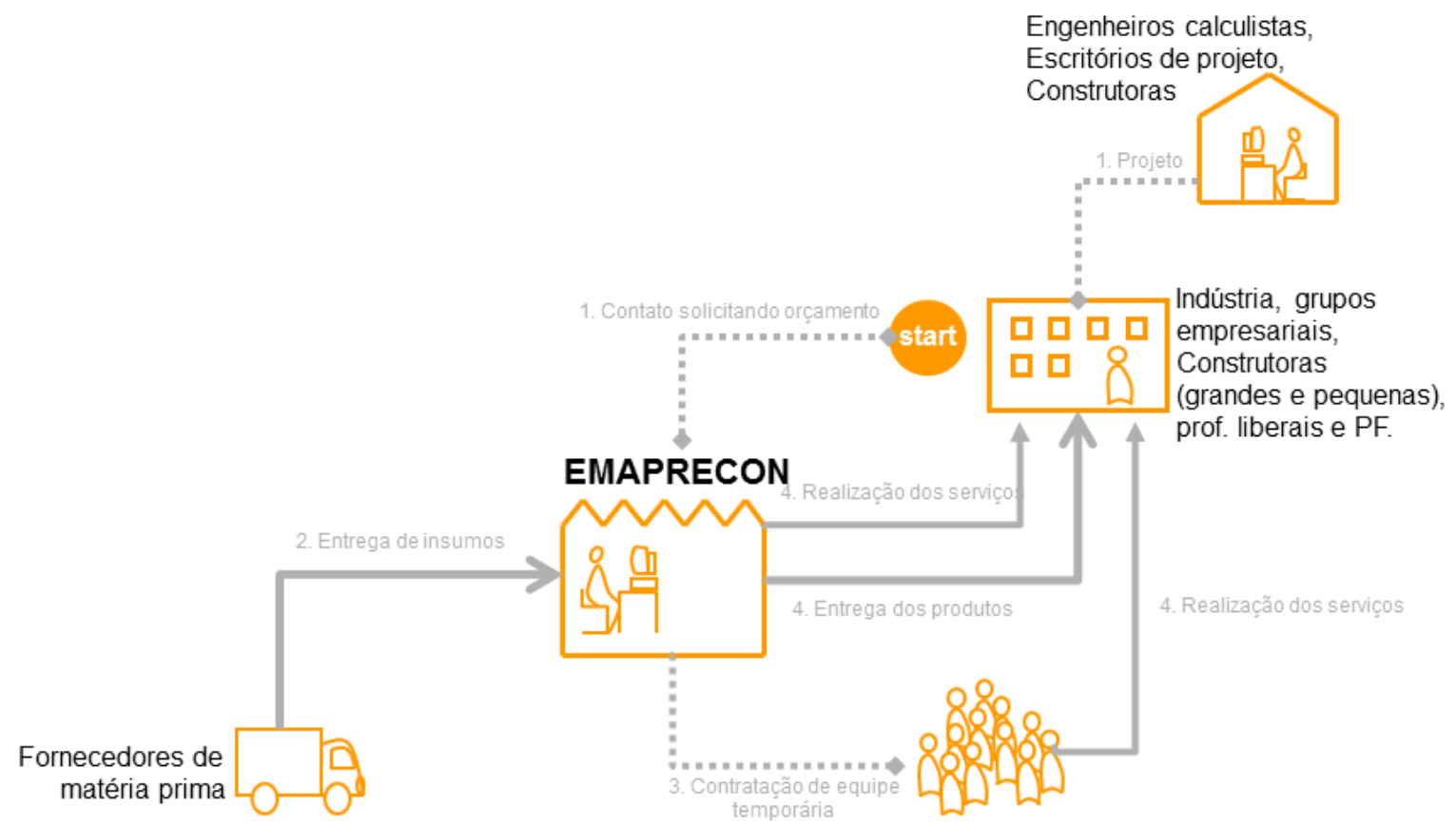

FIGURA 2 - Mapa do sistema 


\subsection{Ciclo de Detalhamento do Sistema}

O objetivo é detalhar os recursos do sistema para permitir a sua execução. Para tanto foram desenvolvidos o diagrama da oferta, o mapa dos recursos requeridos e as atribuições dos cargos no novo modelo de negócios.

O diagrama da oferta é uma representação das funções do sistema. Pode ser usado como ferramenta de projeto e visualização mais detalhada do sistema, para comunicar aos empregados como deve ser o funcionamento do SPS.

O diagrama da oferta é composto por quatro partes: a oferta de valor, cliente, front office e back office. A oferta de valor apresenta os serviços a serem oferecidos. Na parte referente a cliente são apresentadas as ações que se espera que o cliente faça. No front office estão os funcionários que se relacionam diretamente com o cliente. No back office estão os funcionários que dão suporte aos que estão no front office. As ações no front office demandam maior atenção por serem realizadas junto ao cliente e em caso de erro há pouca margem para correções.

Para a construção do diagrama, identificaram-se os elementos para a composição da oferta: orientação técnica, orientações para recebimento de pré-fabricados, projeto (estrutural, complementar e/ou arquitetônico), desenvolvimento de produtos (soluções especiais para demandas específicas), orçamento e planejamento, demolição, canteiro remoto, execução de estruturas in loco, montagem e consolidação, acompanhamento na montagem (nivelamento, aprumo, alinhamento) e assistência técnica.

Cada serviço gerou um fluxo de atividades para a sua efetivação, onde é prevista a ação de cada uma das outras três partes do diagrama da oferta: cliente, front office e back office. Estas ações podem ser interligadas com outros serviços, estabelecendo-se o relacionamento entre as áreas (Figura 3).

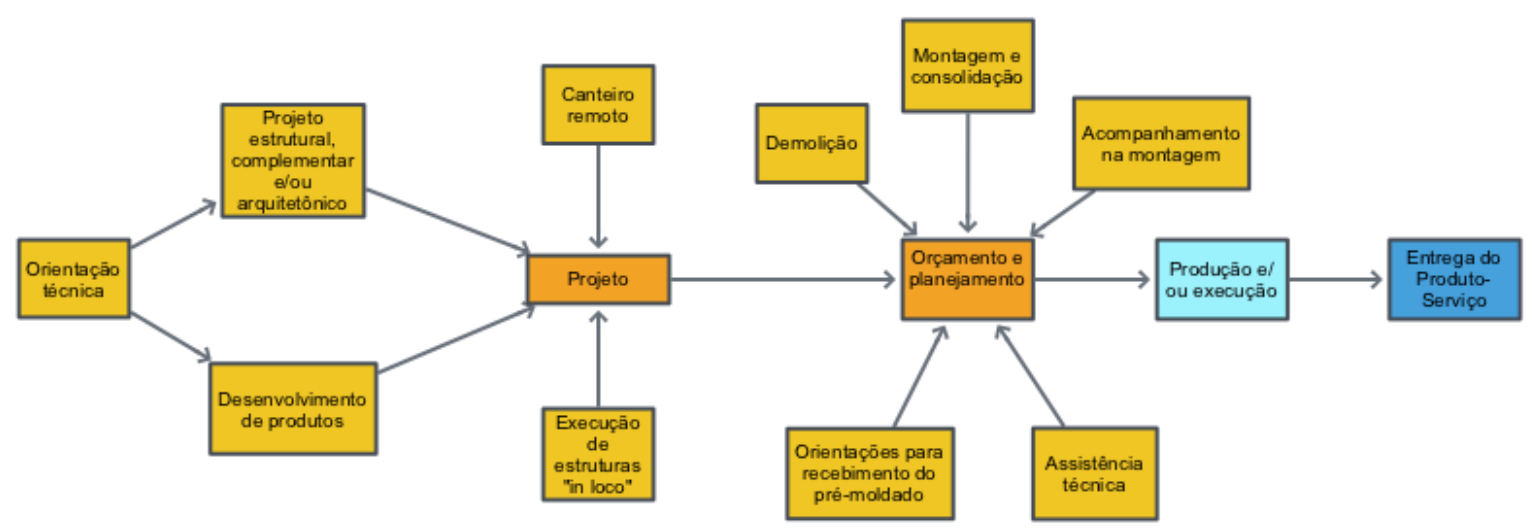


FIGURA 3 - Diagrama da oferta

Em seguida passou-se para a construção do mapa dos recursos requeridos pelo sistema (SPS) que objetiva a descrição do papel dos diferentes intervenientes na concepção, produção ou fornecimento dos elementos (materiais e imateriais) que compõem o sistema. Verificou-se a possibilidade de reunir os serviços em grupos para facilitar a organização do trabalho (Quadro $3)$.

QUADRO 3 - Agrupamento dos serviços oferecidos

\begin{tabular}{|c|c|c|}
\hline \multirow{5}{*}{$\begin{array}{l}\text { SERVIÇOS } \\
\text { PRÉ- } \\
\text { PRODUÇÃO }\end{array}$} & \multirow{2}{*}{ ORIENTAÇÃO } & Orientação técnica \\
\hline & & Orientações para recebimento de pré-fabricados \\
\hline & \multirow{3}{*}{ PROJETO } & $\begin{array}{l}\text { Projeto (estrutural, complementar e/ou } \\
\text { arquitetônico) }\end{array}$ \\
\hline & & $\begin{array}{l}\text { Desenvolvimento de produtos (soluções especiais } \\
\text { para demandas específicas) }\end{array}$ \\
\hline & & Orçamento e planejamento \\
\hline \multirow{6}{*}{$\begin{array}{l}\text { SERVIÇOS } \\
\text { PÓS- } \\
\text { PRODUÇÃO }\end{array}$} & \multirow{3}{*}{$\begin{array}{l}\text { EXECUÇÃO } \\
\text { DE OBRAS }\end{array}$} & Demolição \\
\hline & & Canteiro remoto \\
\hline & & Execução de estruturas in loco \\
\hline & \multirow{3}{*}{ MONTAGEM } & Montagem e consolidação \\
\hline & & $\begin{array}{l}\text { Acompanhamento na montagem (nivelamento, } \\
\text { aprumo, alinhamento) }\end{array}$ \\
\hline & & Assistência Técnica \\
\hline
\end{tabular}

O mapa dos recursos requeridos identificou as funções necessárias para a execução dos serviços listados anteriormente (Diretor Técnico, Engenheiro de Projetos, Engenheiro de Contratos, Engenheiro Residente, Gerente de Produção, Técnico de Qualidade e Encarregado de Produção). Em seguida, a partir de discussões entre os membros do grupo, construiu-se uma matriz que relaciona as funções (cargos) com os serviços.

\section{CONSIDERAÇÕES FINAIS}

O trabalho apresentou as etapas do desenvolvimento e implantação de um SPS em uma empresa que não possuía inicialmente serviços na oferta de valor aos seus clientes e com o cliente mantendo a propriedade do produto. Os resultados apresentados são de interesse para empreendimentos que possuem realidade semelhante em virtude de que na bibliografia atual há 
ênfase em estudos de casos em que a propriedade do produto é da empresa, restringindo a disseminação do conceito do SPS e sua aplicação.

Outro resultado relevante está relacionado ao detalhamento do desenvolvimento do SPS. Nas publicações existentes sobre o tema observam-se poucas informações sobre o desenvolvimento prático de SPS, gerando inúmeras dúvidas sobre como efetivamente realizar esta tarefa.

Os benefícios gerados pela implantação do SPS na empresa permitiram que a mesma sobrevivesse à recente crise econômica brasileira, que afeta com mais intensidade o setor da Construção Civil, complementando o seu faturamento com serviços associados aos produtos físicos fornecidos. Apesar dos resultados positivos já observados no curto prazo, a avaliação dos benefícios para o desempenho e sustentabilidade econômico-financeira para a empresa e a satisfação dos clientes estão sendo monitorados e serão analisados a partir do acumulo de dados sobre o desempenho do SPS implantado.

\section{REFERÊNCIAS}

CLAYTON, R. J.; BACKHOUSE, C. J.; DANI, S. Evaluating existing approaches to product service system design. Journal of Manufacturing Technology Management, v. 23, n. 3, p. 272-298, 2012.

COUGHLAN, P.; COGHLAN, D. Action research for operations management. International Journal of Operations \& Production Management, v. 22, n. 1995, 2002.

NGUYEN, H. N.; SCHNÜRMACHER, C.; STARK, R. Research on how to introduce the PSS engineering into industry. Procedia CIRP, v. 16, p. 74-79, 2014.

OSTERWALDER, A.; PIGNEUR, Y. Business Model Generation. New Jersey: John Wiley \& Sons, 2010.

TUKKER, A. Eight Types of Product-Service System: eight ways to sustainability? Business Strategy and the Environment, v. 260, n. 13, p. 246-260, 2004.

VEZZOLI, C.; KOHTALA, C.; SRINIVASAN, A. Product-Service System Design for Sustainability. 1st. ed. Sheffield: Greenleaf Publishing, 2014. 